\title{
Returning home: Effects of COVID-19 on migrant households in Bihar
}

UNICEF

Population Council Institute

Follow this and additional works at: https://knowledgecommons.popcouncil.org/departments_sbsr-pgy

Part of the Demography, Population, and Ecology Commons, International Public Health Commons, and the Public Health Education and Promotion Commons How does access to this work benefit you? Let us know!

\section{Recommended Citation}

UNICEF and Population Council Institute. 2020. "Returning home: Effects of COVID-19 on migrant households in Bihar," COVID-19 Research Results Brief \#5. New Delhi: UNICEF and Population Council Institute. 
RETURNING HOME:

\section{EFFECTS OF COVID-19 ON MIGRANT HOUSEHOLDS IN BIHAR}

\section{BACKGROUND}

- Many migrants from metro cities of India began to return to their native places with the rise in COVID19 cases in the cities and the extension of lockdown till May 31, 2020; With relaxation of travel restrictions, Bihar started receiving migrants returning home. The government made arrangements for them to be quarantined before they travelled to their villages and homes.

- The key objectives of this study are to understand the extent of return migration, impact of lockdown on migrant household livelihoods and the opportunities for household economic revival through social protection schemes.

\section{METHODS}

- Data was gathered between May 13-22, 2020 from the existing study cohort of households under the project UDAYA (www.projectudaya.in).

- Interviews were conducted with a total of 794 participant households enrolled. Of the 794 households, 264 were migrant households.

- Eligibility: Young boys/girls who were UDAYA participants consented to participate in the regular surveys. Participants who responded to the survey were members of migrant households.

\section{PROFILE AND MIGRATION STATUS}

Profile of study participants:

- Mean age (SD): 23.5 years ( 7.3 years); Males - 33\%; Females: 67\%; Currently married - 60\%; Caste:

Scheduled caste/tribe (SC/ST) - 18\%, Other backward castes $(\mathrm{OBC})-64 \%$, General caste $-18 \%$.
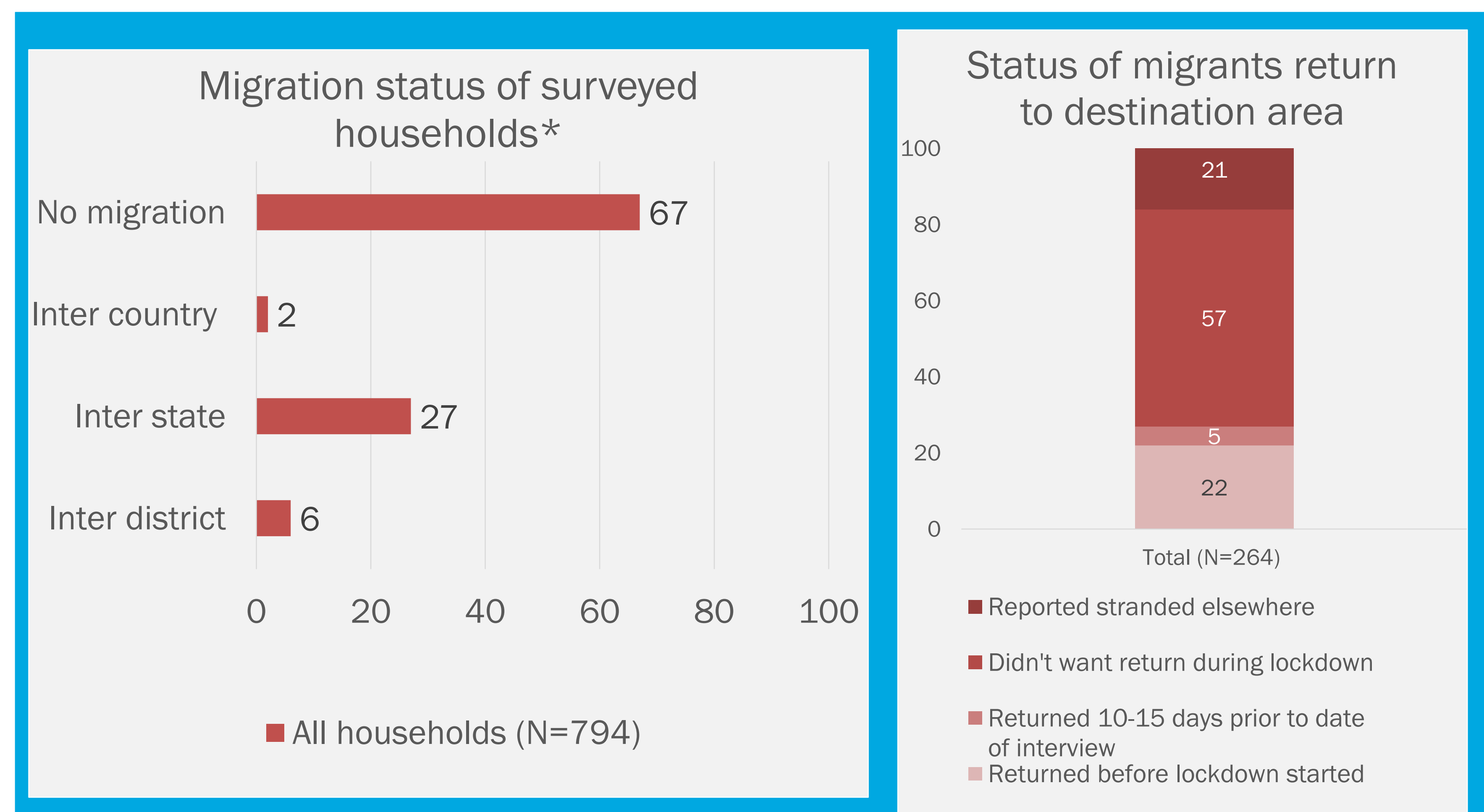

Categories are not mutually exclusive

Migrants from Bihar work in the following states: Delhi - 29\%, Maharashtra - 11\%, Punjab - 11\%, Haryana - 8\%, West Bengal - $6 \%$, UP - 5\%, Karnataka - 4\%.

Perceived risk of getting COVID-19 among migrant households

Lockdown 4.0

Lockdown 1.0

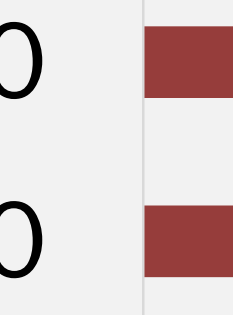

No

0 50 100

Perceived risk of getting COVID-19 continues to be low despite households experiencing return migration.
While there is considerable return migration, not all migrant households reported having their family member returned. Thus, among migrant households, about half of them may experience return migration.

Most of those who returned intend to go back to destination areas in 4-5 months. However, they may experience economic hardship without enough jobs or income.

Half of the migrant households received governmental assistance. And only three-fifths of migrant households reported sufficiency of ration received. Immedlate financial or work for cash assistance shall be extended to rural migrant households, especially to those who lost jobs or income.

\section{IMPACT OF LOCKDOWN ON MIGRANT HOUSEHOLDS}

Impact of lockdown on migrant household earnings

Duration for which households with complete loss of income have financial resources to sustain

Complete loss of income

Major reduction

in income

Minor effect

No impact

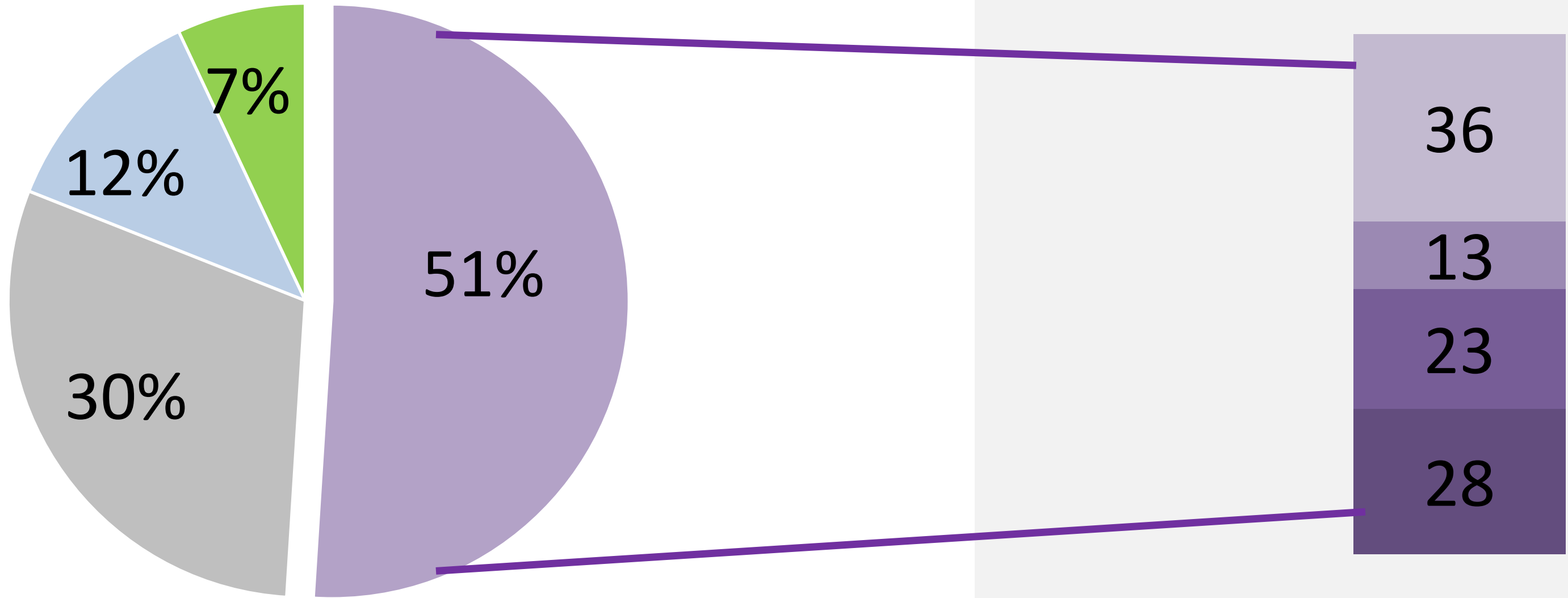

More than one

month

Two weeks to one

month

One week to two

week

Less than a week
About half of the households lost complete income. Over two-thirds of the households who reported complete loss of income due to lockdown reported that they have finances that are sufficient for only less than a month

- Job loss was relatively higher among the SC/STs. About one-fifth of them reported that their primary source of income was from government schemes.

- Almost all migrant households received ration from the public distribution system (PDS), although only $42 \%$ reported sufficiency of ration.

More than half of the migrant households received financial assistance from the government and the average amount received was Rs.1320.

- About $20 \%$ of migrant households reported that their family members were stranded.

- Among those who returned, almost everyone reported that they will go back to destination areas for work.

- About $70 \%$ reported that they will go to destination areas in an average time of 4.4 months.



Note: Results for select categories may be interpreted with caution due to low sample size.

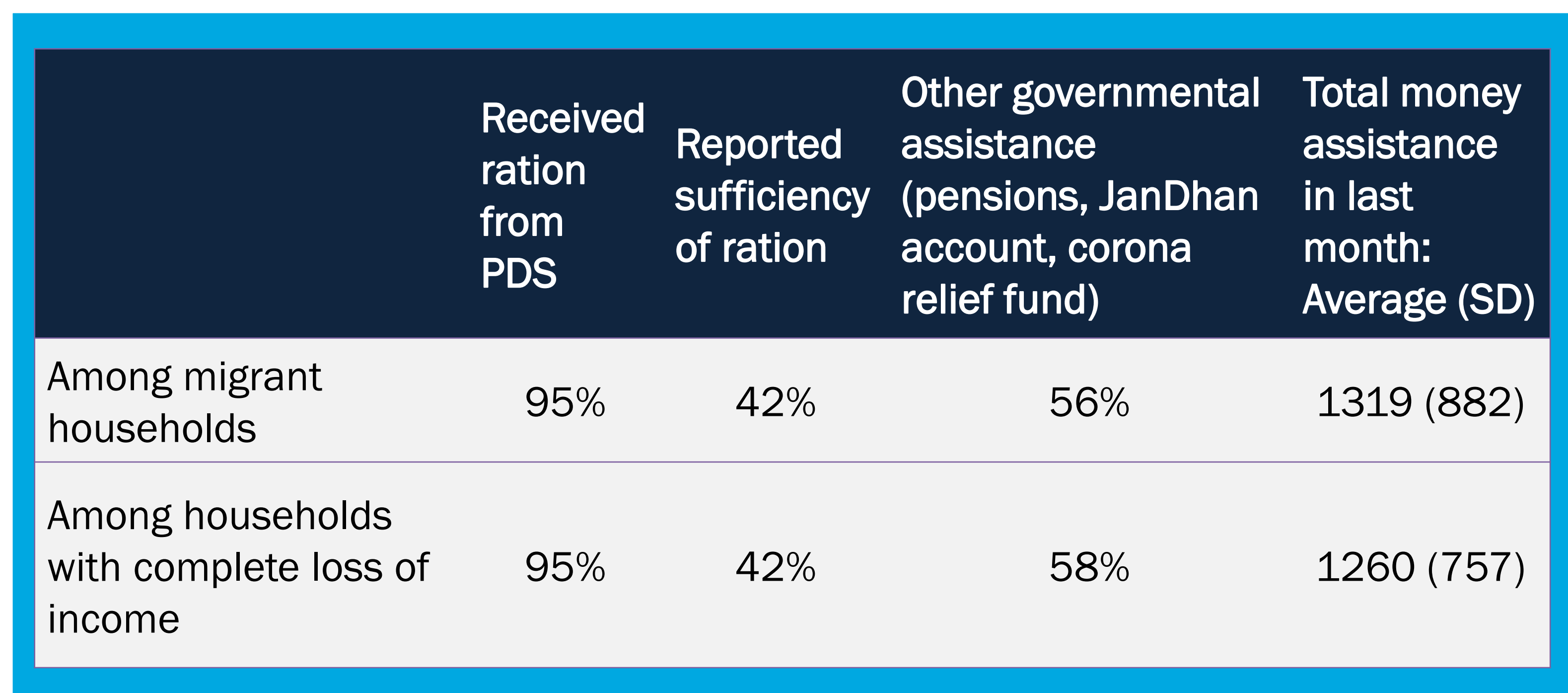

Percent migrants who reported intention to go back to destination areas among those who returned to Bihar at the time of survey $(n=71)$

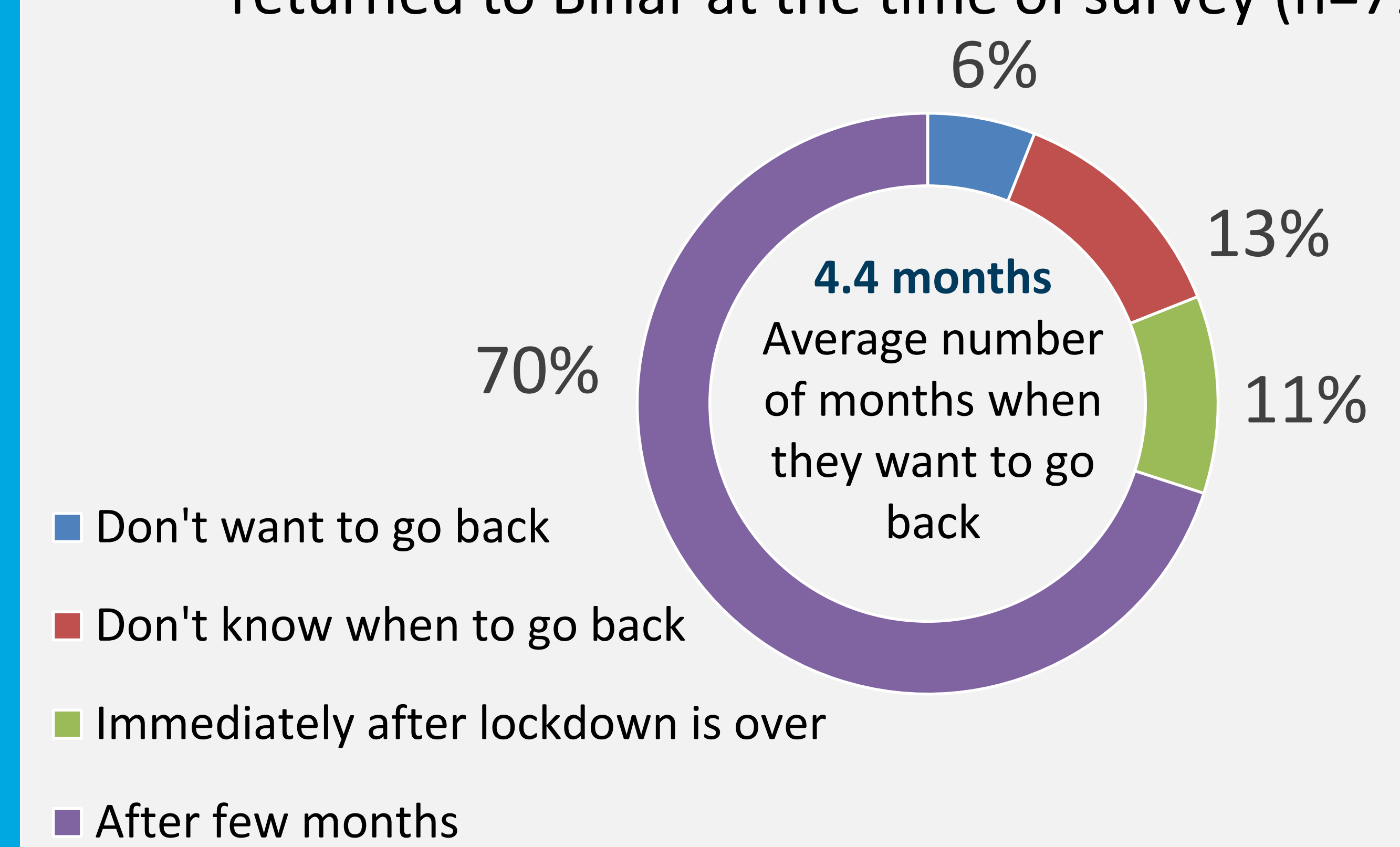

\section{LIMITATIONS}

Results of this brief may be interpreted cautiously due to certain limitations. First and foremost, the survey was conducted among UDAYA cohort of migrant households who had access to phones and consented to participate in the survey. Further, the survey was conducted during the first few days of Lockdown 4.0 in May 2020, around the time when migrants started returning home. Due to this, not many migrant households received their family members back home before the end of the survey. Finally, the brief presents results only of access to services among migrant households.

\section{CONTACT INFORMATION}

This work was jointly undertaken by Population Council Institute and UNICEF/Bihar. For more information, contact nsaggurti@popcouncil.org; aporwal@popcouncil.org; pash@unicef.org 